\title{
Effect of heat treatment on optical properties of crosslinkable Azo Chromophore doped in poly amic acid
}

S. Hamedi

S_hamedi@shirazu.ac.it

A. Gharavi
agharavi@shayda.com
Photonics Laboratory, Department of Electrical Engineering, Shiraz University, KarimKhan Zand Street, Shiraz, Iran

Photonics Laboratory, Department of Electrical Engineering, Shiraz University, KarimKhan Zand Street, Shiraz, Iran

In this work, we have studied the optical properties of a crosslinkable poly amic acid containing Disperse Red 1. The thin films were cured at 130,160 and $195^{\circ} \mathrm{C}$. The structural and optical properties of the doped films were investigated by using UV-VIS spectra, and Prism Coupling techniques. The composite crosslinks during poling rendering it totally insoluble. A $r_{33}$ of $1.5 \mathrm{pm} / \mathrm{v}$ was obtained after poling.

[DOI: http://dx.doi.org/10.2971/jeos.2015.15048]

Keywords: Azo chromophore, poly amic acid, thermal annealing, waveguiding, $\mathrm{r}_{33}$

\section{INTRODUCTION}

Optoelectronic polymeric materials have attracted interest because of their application in various devices such as modulators, switches, and detectors [1]-[3]. With the advances in optical communications, azo Electro-optic (EO) chromophores have been studied for a wide range of applications such as optical network components, optical interconnects and photonic devices $[4,5]$. They have large EO coefficients, low optical loss, as well as high bandwidth. They are easy to process and have relatively low cost of production [1], [6]-[8]. There is a broad range of EO devices, having a waveguide structure such as Mach-Zehnder modulators, couplers [3]-[6] gratings [9], and photonic crystal [10], that can be fabricated based on the cistrans property of azo chromophores.

Azo chromophores have been used as guests, side groups, or main-chain segments in polymers [11]. DR1 is often doped in PMMA as guest-host, which has a glass transition (Tg) of about $123^{\circ} \mathrm{C}$. Further increase in glass transition through the use of polyimides can reduce orientation mobility in poled polymers at elevated temperature $[12,13]$. EO polymers consist of dipole moments which can be poled with high electric fields and will be used as EO devices [14, 15]. Poling process involves applying an electric field to the film heated to near its glass transition temperature to align the chromophores [16]. High glass transition is an important parameter in the stability of EO devices.

Here we have developed a cross linkable system that maintains the ease of fabrication of a doped system while maintaining the properties of a functionalized system. Our experiment is aimed to understand the optical properties of a high glass transition polymer (PAM) doped with azo chromophore (DR1).

\section{EXPERIMENTAL SECTION}

Disperse Red 1(DR1) was used as chromophore doped in Poly (pyromellitic dianhydride-co-4, 4'-oxydianiline), amic acid solution (PAM) available from Sigma-Aldrich. Chromophores (DR1) are doped in poly amic acid and are heated to imidization temperature $\left(200^{\circ} \mathrm{C}\right)$ resulting in a polyimide with strongly bonded DR1. The high glass transition of polyimides gives the material a high thermal and temporal stability. The structures of the azo chromophore and the host polymer are shown in Figure 1. The chromophore was doped at 10, 28 and $40 \mathrm{wt} \%$ into the host polymer. The solution was filtered through a $0.2 \mu \mathrm{m}$ filter and was spin coated onto a glass substrate. For films with thicknesses of about 3-4 $\mu$ m, spin coating was used with a $10 \mathrm{~s}$ spin at $3200 \mathrm{rpm}$. Spin coated films were baked to $70^{\circ} \mathrm{C}$ for 15 minutes to remove the solvent.

\section{RESULTS AND DISCUSSION}

Annealing and curing relays the polymer chains reducing the free volume in the bulk polymer. This densification restricts the chromophore reorientation making the NLO material more stable as a whole. The optical absorbance of the film was measured by a UV-VIS spectrometer in the wavelength range from 300 to $1100 \mathrm{~nm}$. Figure 2 shows the absorption spectrum of the film before and after curing temperatures of $100^{\circ} \mathrm{C}$ to $195^{\circ} \mathrm{C}$. Before curing, maximum absorption peak is at a wavelength of $519 \mathrm{~nm}$, but after heating to $195^{\circ} \mathrm{C}$ its absorption dropped by about $50 \%$ in the wavelength of $495 \mathrm{~nm}$. The observed blue shift in the absorption peak is an indication of affected conjugation by the imidization process.

At the same time there is a $50 \%$ decrease in the chromophores absorption which is an indication of chromophores disinte- 
<smiles>CCN(CCO)c1ccc(N=Nc2ccc([N+](=O)[O-])cc2)cc1</smiles>

DR1<smiles>CCc1ccc(Oc2ccc(NC(=O)c3cc(C(=O)NC(C)(C)C)c(CO)cc3C(=O)O)cc2)cc1</smiles>

Poly Amic Acid

FIG. 1 Chemical structures of azo chromophore and host polymer.

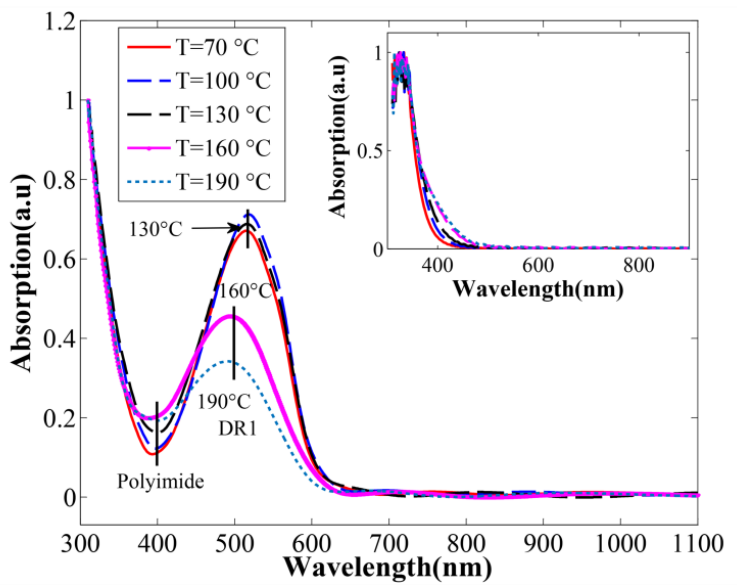

FIG. 2 Absorption spectrum of PAM: DR1 (10 wt\%) before and after annealing temperatures from $70^{\circ} \mathrm{C}$ to $195^{\circ} \mathrm{C}$. The inset shows absorption spectrum of poly amic acid.

gration in the imidization process. Thermal treatment of the polymer close to $\mathrm{Tg}\left(200^{\circ} \mathrm{C}\right)$, results in reorientation of dipole moments, crosslinking and rearrangement of polymer chains. The blue shift is an indication of inhibition in the strength of the electron accepting/ withdrawing group. This is an indication of chemical alteration of either, the electron withdrawing group (NO2) or the electron donating amine group (N). Since the shift is weak therefore we can conclude that any modification of chromophore is occurring from the amine side of the chromophore. At the same time when cured at temperatures of $130^{\circ} \mathrm{C}$ and above, the doped polymer becomes insoluble and will not dissolve in anything including DMF and no leaching-out of the chromophore occurs. This indicates that the chromophore is bonded strongly to the polymer chain. The chemical analysis of the process will be reported separately.

The film thickness and refractive index were measured by a computer controlled prism coupler using the attenuatedtotal-reflection (ATR) technique [17]. The characteristic coupling modes $(\mathrm{m}=0,1,2, \ldots)$ in the film were determined. The ATR spectrum of PAM: DR1 with TM polarization is represented in Figure 3. Using these coupling modes a refractive index of $n=1.617$ is obtained for the film before curing and a refractive index $n=1.649$ after curing for the $10 \mathrm{wt} \%$ doped film. At the same time the thickness was decreased by $1 \mathrm{mi}-$



FIG. 3 ATR spectrum of PAM: DR1 (10 wt\%) thin film for coupled light withTM polarization, (a) before curing (b) after curing at $195{ }^{\circ} \mathrm{C}$. $\mathrm{t}$ is the film thickness and $\mathrm{n}$ is refractive index of the film.
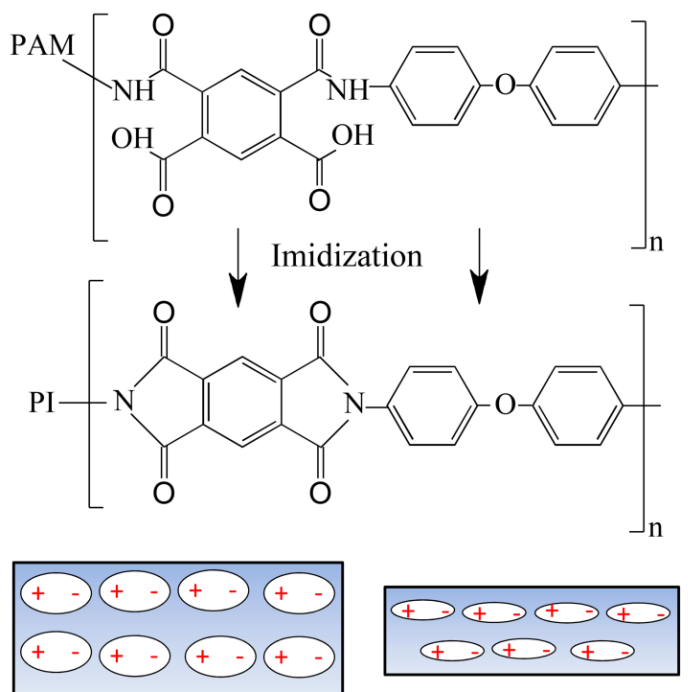

(a) Guest/host film $\quad$ (b) Imidization and densification

FIG. 4 Processing of PAM films containing DR1. (a) guest-host poly amic acid film and (b) imidization process restricting chromophore mobility.

cron (40\%). The modes show the coupling angles of the laser light into the film which is very sensitive to thickness and refractive index. A change in the thickness changes mainly the number of modes whereas a change in refractive index essentially shifts the position of the coupling angles. When the film is heated to near $\operatorname{Tg}\left(200^{\circ} \mathrm{C}\right.$. $)$, it causes the poly amic acid (host) to crosslink and form imide rings (Figure 4). This causes a decrease in film thickness by $40 \%$, further limiting the reorientational mobility of the guest chromophores. The chemical reaction and imidization during curing process also causes good adhesion to the substrate. The film removal is only possible with a rasor blade. When cured at $195^{\circ} \mathrm{C}$, the guest-host composite becomes insoluble and chromophores wont separate and leach out of the host there after. There may be some covalent or hydrogen bonding occurring between the polymer and the chromophore and it may have become functionalized to the polymer chain.

The coupled light into the slab wave guide is represented in Figure 5. The guiding path is clearly observed by the scattered light through the waveguide. As measurements show, prism coupling becomes more difficult after annealing and 




(Coupling prism position)

FIG. 5 The coupled light with wavelength of $832 \mathrm{~nm}$ into a $2 \mathrm{~cm}$ long slab waveguide, (a) before curing, (b) after curing at $195{ }^{\circ} \mathrm{C}$ for about 5 minutes. The waveguiding brightness and output light of the film decreased after curing. Waveguiding trace is clearly visible in the picture due to scattering along waveguide path. The path is less visible after curing (b)

\begin{tabular}{cc}
\hline DR1 content $(\mathrm{wt} \%)$ & $\mathrm{r}_{33}(\mathrm{pm} / \mathrm{v})$ \\
\hline 7 & 0.22 \\
10 & 0.55 \\
28 & 1.44 \\
40 & 1.68 \\
\hline
\end{tabular}

TABLE 1 E0 coefficient $\left(r_{33}\right)$ for different amounts of azo chromophore (DR1) content doped in poly amic acid.

curing because the film becomes harder and prism contact to the polymer becomes less intimate resulting in less light coupling into the film. Propagation loss for films at temperatures of 70,130 and $190^{\circ} \mathrm{C}$ was measured. In order to measure the slabs propagation loss, we used a CCD image of the guiding path. We calculated the loss by measuring the intensity average of the pixels of coupled light across the width of the slab waveguide (bright path), and then fitting the intensities to the absorption exponential $I_{0} e^{-\alpha x}$ and then applying formula (1), where $x_{1}$ and $x_{2}$ are two arbitrary positions along the waveguide, and $\alpha$ is the absorption coefficient obtained by fitting the absorption exponential.

$$
L=\frac{-10}{x_{2}-x_{1}} \log \frac{I\left(x_{2}\right)}{I\left(x_{1}\right)}=\frac{-10}{x_{2}-x_{1}} \log \frac{I_{0} e^{-\alpha x_{2}}}{I_{0} e^{-\alpha x_{1}}} \quad(\mathrm{~dB} / \mathrm{cm})
$$

Results of the measurements at $70^{\circ} \mathrm{C}$ are shown in Figure 6. The output signal from the camera versus distance was plotted for a $6 \mathrm{~mm}$ segment of the waveguide. From the image it was calculated that $1 \mathrm{~mm}$ length of the film is equal to 19 pixels. The trend of the signal versus distance along the waveguide illustrates a decrease in the intensity due to the propagation loss, as seen in Figure 6. The summery of the propagation loss before and after annealing is represented in the inset of Figure 6. EO coefficient measurements for different concentrations of chromophore in poly amic acid are represented in Table 1. To align chromophores we used the corona poling method with a corona voltage of about $\mathrm{V}_{\mathrm{dc}}=4 \mathrm{kV}$ applied to the tungsten wire, $1 \mathrm{~cm}$ above the surface of the film. The temperature was set at $190^{\circ} \mathrm{C}$, close to the glass transition temperature (Tg) of the polymer for $20 \mathrm{~min}$. To prepare the film for EO measurement, the polymer was coated on a ITO glass substrate and then poled. $100 \mathrm{~nm}$ aluminium (Al) was evaporated

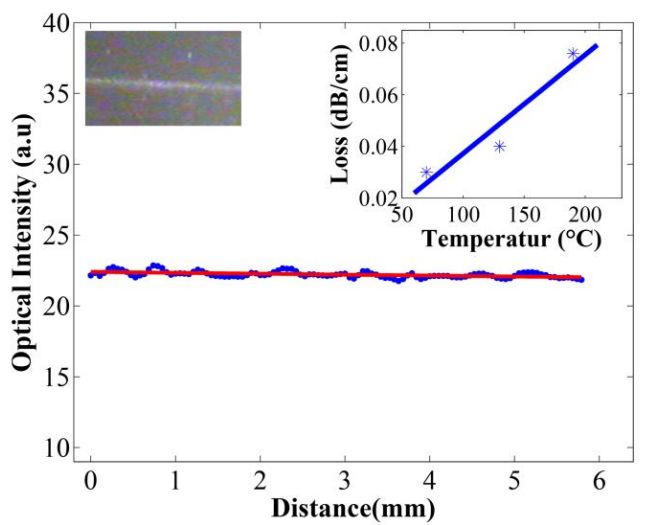

FIC. 6 Measured intensity of coupled light vs distance for $5.78 \mathrm{~mm}$ length of polymeric slab waveguide before annealing. Each dotted line is the average of the intensity of the coupled light across the width of the slab waveguide and dark line is the fitted absorption exponential. The inset (left) shows coupled light with a wavelength of $980 \mathrm{~nm}$ into thin film as a slab waveguide observed from above by a CCD camera. The inset (right) shows the variation of loss with annealing temperature.

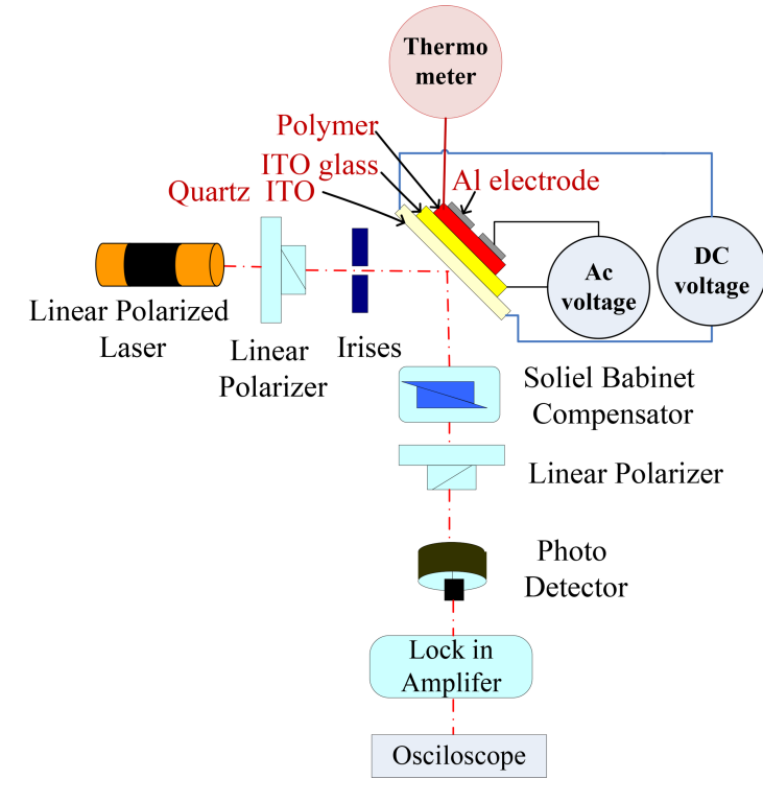

FIC. 7 Teng and Man experimental setup for insitu measurement of EO coefficient $\left(r_{33}\right)$ of the polymer PAM:DR1 $(40 \mathrm{wt} \%)$ and increasing temperature to $\operatorname{Tg}\left(200^{\circ} \mathrm{C}\right)$ for thermal stability measurement of the poled polymer.

on the poled polymer using a shadow mask with $4 \mathrm{~mm}$ diameter holes. The EO coefficient of the poled polymer film was measured by the Teng and Man reflection technique [18] with a polarized laser beam at a wavelength of $688.7 \mathrm{~nm}$. A modulating voltage up to $10 \mathrm{~V}$ was applied across the electrodes at a frequency of $1 \mathrm{kHz}$ as shown in Figure 7. The EO coefficient $\left(r_{33}\right)$ of the poled polymer is determined by Eq. (2):

$$
r_{33}=\frac{3 \lambda I_{m}\left(n^{2}-\sin ^{2} \theta\right)^{3 / 2}}{4 \pi V_{m} I_{c} n^{2}\left(n^{2}-2 \sin ^{2} \theta\right) \sin ^{2} \theta}
$$

Where $n$ is the refractive index of the polymer, $I_{m}$ is the modulated beam intensity, $V_{m}$ is the input AC voltage and $\theta$ is the incident angle upon the sample. The setup arrangement is shown in Figure 7. As shown in Table 1 the EO coefficients become larger with higher chromophore concentration. For the $40 \mathrm{wt} \%$ chromophore, the surface smoothness of the film and also the mechanical integrity of the film were severely compromised. But for up to $28 \mathrm{wt} \%$ chromophore concentration 




FIC. 8 Thermal stability of Electro-0ptic coefficient of $40 \mathrm{wt} \%$ concentration of chromophore versus temperature as heating from room temperature to $\mathrm{Tg}$. Temperature dependence of the decay of the EO coefficient ( $\mathrm{r} 33$ ) of $40 \mathrm{wt} \%$ concentration of chromophore PAM:DR1 $(40$ wt\%).

the optical and mechanical properties of the film were good before and after curing. For thermal stability measurements we used insitu measurement of $r_{33}$ coefficient while heating from room temperature to $200^{\circ} \mathrm{C}$ in the Teng and Man setup as shown in Figure 7. A semitransparent quartz coated indium tin oxide (ITO) with a resistivity of $15 \Omega / \mathrm{cm}^{2}$ is used as transparent heater. A DC voltage up to $30 \mathrm{~V}$ was applied to the ITO quartz for heating the film to $200^{\circ} \mathrm{C}$ and the temperature of the film was monitored with a thermometer. While increasing the temperature, a polarized laser beam is passed through a polarizer, at an angle of $45^{\circ}$ to the ITO coated quartz. The beam then passes through the glass substrate, ITO, the poled polymer and is reflected back out through the layers into the air by the $\mathrm{Al}$ electrode. The reflected beam passes through a SoleilBabinet, at an angle of $45^{\circ}$ from the axes of the sample and the polarizer. The birefringence of the sample causes a phase retardation in the light detected by the photodiode (PD). Figure 8 shows the degradation of $\mathrm{r}_{33}$ with temperature. As shown in Figure 8 , at $80^{\circ} \mathrm{C}$, no decay of the measured coefficients is observed. At $120^{\circ} \mathrm{C}$, about $50 \%$ of the original $r_{33}$ value is maintained. At higher temperatures, we observe a significant decrease in EO coefficient. Heating to temperatures near the glass transition decreases the poling quite rapidly.

\section{CONCLUSION}

High levels of doping are possible with PAM:DR1 system. The imidization process at $\approx 190^{\circ} \mathrm{C}$ functionalizes the chromophore in such away so that the chromophores bond to the host polymer. However high curing temperatures pose a problem with DR1. As it appears DR1 decomposes starting at $130^{\circ} \mathrm{C}$. This decomposition reduces the nonlinearity of the material. Choosing a more thermally stable chromophore could solve this problem.

\section{References}

[1] P. A. Sullivan, B. C. Olbricht, and L. R. Dalton, "Advances in organic materials for optical modulation," J. Lightwave Technol. 26, 2345-2354 (2008).
[2] W. Wang, Y. Shi, D. Olson, W. Lin, and J. H. Bechtel, "Push-Pull Poled Polymer Mach-Zehnder Modulators with a Single Microstrip Line Electrode," IEEE Photonic. Tech. I. 11, 51-53 (1999).

[3] S. Hamedi, and A. Charavi, "Fabrication of an AzoPloymeric MachZehnder Electro- Optic Modulator," in Proceedings to 2oth Proc. Iran.Conf. optics and photonics (ICPET, Shiraz, 2013).

[4] H. S. Nalwa, Handbook of Organic Electronics and Photonics (American Scientific Publisher, Stevenson Ranch, 2008).

[5] T. Yoshimura, Thin-Film Organic Photonics: Molecular Layer Deposition and Applications (CRC Press, Baco Raton, 2011).

[6] Y. Enami, D. Mathine, C. T. DeRose, R. A. Norwood, J. Luo, A. K-Y. Jen, and N. Peyghambarian, "Hybrid electro-optic polymer/sol-gel waveguide directional coupler switches," Appl. Phys. Lett. 94, 213513 (2009).

[7] S. S. H. Sun, and L. R. Dalton, Introduction to Organic Electronic and Optoelectronic Materials and Devices (CRC Press, Boca Raton, 2008).

[8] J. Luo, S. Liu, M. Haller, H. Li, T. D. Kim, K. S. Kim, H. Z. Tang, et al., "Recent progress in developing highly efficient nonlinear optical chromophores and side-chain dendronized polymers for electro-optics," P. Soc. Photo-Opt. Ins. 499, 520-529 (2003).

[9] E. Sarailou, A. Charavi, S. Javadpour, and V. Shkunov, "Grating based electro-optic switch with azo nonlinear optical polymers,"Appl. Phys. Lett. 89, 171114 (2006).

[10] H. Karimi-Alavijeh, G. Parsanasab, M. Baghban, and A. Gharavi, "Two-dimensional photonic crystal for optical channel separation in azo polymers," Appl. Optics 48, 3250-3254 (2009).

[11] C. Zhang, H. Zhang, M. Oh, L. Dalton, and W. Steir, "What the ultimate polymeric electro-optic materials will be: GuestHost, Crosslinked, or Side- Chain?," P. Soc. Photo-Opt. Ins. 4991, 537-550 (2003).

[12] C. Park, Z. Ounaies, K. E. Wise, and J. S. Harrison, "In situ poling and imidization of amorphous piezoelectric polyimides," Polymer. 45, 5417-5425 (2004).

[13] J. W. Wu, J. F. Valley, S. Ermer, E. S. Binkley, J. T. Kenney, G. F. Lipscomb, and R. Lytel, "Thermal stability of electrooptic response in poled polyimide systems," Appl. Phys. Lett. 58, 225-227 (1991).

[14] S. Michela, J. Zyssa, I. Ledoux-Raka, C. T. Nguyena, "Highperformance electro-optic modulators realized with a commercial side-chain DR1-PMMA electro-optic copolymer," P. Soc. Photo-0pt. Ins. 7599, 759901 (2010).

[15] S. K. Kim, Q. Pei, H. R. Fetterman, B. C. Olbright, and L. R. Dalton, "Photo assisted corona poled YLD-124/DR1-co-pmma electro optic device using photo isomerization," IEEE Photonic. Tech. I. 23, 845-847 (2011).

[16] A. Donval, E. Toussaerea, S. Brasselet, and J. Zyss, “Comparative Assessment of Electrical,Photoassistedand All Optical In-Plane Poling of Polymer BasedElectroopticModulators," Opt. Mater. 12, 215-219 (1999).

[17] V. Khomchenko, A. B. Sotskv, A. A. Romanenko, and E. V. Glazunov, D. N. Kostyuchenko, "Determination of thin film parameters by prism coupling technique," Tech. Phys. Lett. 28,467-470 (2002).

[18] C. Teng, and H. T. Man, "Simple Reflection Technique For Measuring The Electro Optic Coefficient of Poled Polymers," Appl. Phys. Lett. 56, 1734-1736 (1990). 